\title{
Racial/Ethnic Differences in the Associations of Overall and Central Body Fatness with Circulating Hormones and Metabolic Factors in US
}

\section{Men}

\author{
David S. Lopez,, ${ }^{1,}$ Sabine Rohrmann, ${ }^{2}$ Sarah B. Peskoe, ${ }^{3}$ Corinne E. Joshu, ${ }^{3}$ Konstantinos K. Tsilidis, ${ }^{4}$ \\ Elizabeth Selvin, ${ }^{3}$ Adrian S. Dobs, ${ }^{5}$ Norma Kanarek, ${ }^{5}$ Steven Canfield, ${ }^{6}$ William G. Nelson, ${ }^{7}$ and \\ Elizabeth A. Platz ${ }^{3}$ \\ ${ }^{1}$ UTHealth McGovern Medical School- Division of Urology and UTHealth School of Public Health, Houston, TX \\ ${ }^{2}$ Department of Chronic Disease Epidemiology- University of Zurich, Zurich, Switzerland \\ ${ }^{3}$ Department of Epidemiology, Johns Hopkins Bloomberg School of Public Health, Baltimore, MD \\ ${ }^{4}$ Tsilidis Department of Hygiene and Epidemiology, University of Ioannina, School of Medicine, Ioannina, Greece \\ ${ }^{5}$ Department of Oncology, Johns Hopkins University School of Medicine, Baltimore, MD \\ ${ }^{6}$ UTHealth McGovern Medical School-Division of Urology, Houston, TX \\ ${ }^{7}$ Department of Urology and the James Buchanan Brady Urological Institute, Johns Hopkins University School of Medicine, Baltimore, MD \\ "Corresponding author: David S. Lopez, Division of Epidemiology, Human Genetics and Environmental Sciences, University of Texas- Houston School of Public Health, 1200 \\ Herman Pressler, Suite E-629, Houston, TX 77030. Tel: +1-7135006348, Fax: +1-7135009264, E-mail: David.S.Lopez@uth.tmc.edu
}

Received 2016 December 20; Revised 2017 February 28; Accepted 2017 April 08.

\begin{abstract}
Background: Racial/ethnic disparities in the associations of body fatness with hormones and metabolic factors remain poorly understood. Therefore, we evaluated whether the associations of overall and central body fatness with circulating sex steroid hormones and metabolic factors differ by race/ethnicity.

Methods: Data from 1,243 non-Hispanic white (NHW), non-Hispanic black (NHB) and Mexican-American (MA) adult men in the third national health and nutrition examination survey (NHANES III) were analyzed. Waist circumference (central body fatness) was measured during the physical examination. Percent body fat (overall body fatness) was calculated from bioelectrical impedance. Associations were estimated by using weighted linear regression models to adjust the two measures of body fatness for each other.

Results: Waist circumference, but not percent body fat was inversely associated with total testosterone and SHBG in all three racial/ethnic groups after their mutual adjustment (all $\mathrm{P}<0.0001)$. Percent body fat $(\mathrm{P}=0.02)$, but not waist circumference was positively associated with total estradiol in NHB men; no association was present in NHW and MA men (P-interaction $=0.04)$. Waist circumference, but not body fat was strongly positively associated with fasting insulin (all $\mathrm{P}<0.0001$ ) and inversely associated with HDL cholesterol (all $\mathrm{P} \leq 0.003$ ) in all three racial/ethnic groups. Both percent body fat and waist circumference were positively associated with leptin (all $\mathrm{P}<0.0001)$ in all three racial/ethnic groups.

Conclusions: There was no strong evidence in the associations of sex hormones and metabolic factors with body fatness in different racial/ethnic groups. These findings should be further explored in prospective studies to determine their relevance in racial/ethnic disparities of chronic diseases.
\end{abstract}

Keywords: Obesity, Hormones, Metabolic Factors, Race/Ethnicity, Men

\section{Background}

The prevalence of overweight and obesity, whether measured by the overall amount or distribution of body fat, has been increasing dramatically among American men since 1980 (1); the prevalence is higher in some racial/ethnic minority groups $(1,2)$. The racial/ethnic differences in the prevalence of overweight and obesity are thought, in part, to underlie racial/ethnic disparities in risk of chronic diseases (3-5). Body fat may influence these chronic diseases via alterations in sex steroid hormones, insulin, and inflammatory mediators (6-8). We previously observed in men in the US national health and nutrition examination survey III (NHANES III) that percent body fat or waist circumference (WC) was inversely associated with serum total testosterone and sex hormone binding globulin (SHBG) concentrations and positively associated with total estradiol after adjusting for race/ethnicity (9). Also in NHANES III, we found that serum total testosterone concentration was highest in MA's compared with NHB and NHW men (10). 


\section{Objectives}

We evaluated whether the association of measures of overall (body mass index (BMI) (11)) and central (waist circumference) body fatness with sex steroid hormones and metabolic factors differs among NHW, NHB, and MA men.

\section{Methods}

\subsection{Study Population}

NHANES III used a multistage stratified and clustered probability sampling, in which MA's, NHB's, and the elderly were oversampled to ensure adequate samples sizes, and it is weighted to represent the total US civilian, noninstitutionalized population.

NHANES III had two phases (1988 - 1991 and 1991 - 1994) from which independent, unbiased national estimates of health and nutrition can be produced. Race was selfreported. For Hispanic ethnicity, hand cards were used to determine Mexican/Mexican-American ancestry. From these race and ethnicity categories, we classified the participants for this analysis as NHW, NHB, MA (12). For studies on sex steroid hormones, we selected men who participated in the morning session to reduce diurnal variation in serum levels conditions (13). Men with a history of prostate cancer were excluded to minimize the possible effects of treatment on serum levels $(n=12)$ and other covariates ( $n$ $=209$ ) leaving a total of 1,243 men for the analyses.

Participants were interviewed and underwent an extensive physical examination during which a trained examiner measured height, weight, and waist circumference. Cigarette smoking, alcohol consumption, and physical activity were assessed by questionnaire. Body mass index (BMI) was calculated as weight (kilograms) divided by the square of height (meters). Percent body fat was calculated from bioelectrical impedance analysis and weight measurements using previously published formulas (14).

\subsection{Measurement of Circulating Hormones and Metabolic Fac-} tors

Serum concentrations of total testosterone, total estradiol, and SHBG were previously measured in Dr. Nader Rifai's laboratory at Children's hospital (Boston, MA) by electrochemiluminescence immunoassays on a 2010 Elecsys autoanalyzer (Roche Diagnostics, Indianapolis, IN). The lowest limits of detection were $0.02 \mathrm{ng} / \mathrm{mL}$ for testosterone, $5.00 \mathrm{pg} / \mathrm{mL}$ for estradiol and $3.00 \mathrm{nmol} / \mathrm{L}$ for SHBG; no samples had concentrations below the limit of detection (LOD) for these analytes. Calculated free testosterone and free estradiol concentrations were estimated from total testosterone and total estradiol, respectively, and SHBG, and albumin concentrations using mass action equations $(15,16)$. Detailed information on the laboratory methods used and quality measures for metabolic factors in NHANES III have been reported previously $(13,17,18)$.

\subsection{Statistical Analyses}

All statistical analyses were performed using SUDAAN (19) as implemented in SAS v.9.1 (Cary, NC) software. Sampling weights were applied in linear regression models to take into account selection probabilities, over-sampling, non-response, and differences between the sample and the total US population. To normalize the hormone and metabolic factor distributions (dependent variables), we transformed the concentrations using the natural logarithm. We ran multivariable linear regression models by race/ethnicity with either percent body fat or waist circumference entered as a continuous variable (independent variables) adjusting for age, smoking status, cotinine concentration, alcohol consumption and physical activity. To assess whether race/ethnicity modifies underlying relationships, we tested for interaction between race/ethnicity and the two body fatness measures using the likelihood ratio test.

We also estimated geometric mean hormone and metabolic factor concentrations by race/ethnicity in three joint categories of overall and central body fatness: 1) obese-high (percent body fat $\geq 25 \%$ )/ high (waist circumference $\geq 102 \mathrm{~cm}), 2$ ) obese on one measure only: -high ( $\geq$ $25 \%) / \operatorname{normal}(<102 \mathrm{~cm})$ or normal $(<25 \%) / \operatorname{high}(\geq 102 \mathrm{~cm})$, and 3) non-obese - normal $(<25 \%) /$ normal $(<102 \mathrm{~cm})(20$, 21). We compared geometric mean concentrations among the three categories of body fatness by race/ethnicity using ANOVA. All P-values were from two-sided tests.

\section{Results}

\subsection{Characteristics by Body Fatness Categories Within Race/Ethnicity Groups}

In Table 1 we describe the baseline characteristics of the men by joint category of overall and central body fatness (obese, obese on one measure only, non-obese) within the three race/ethnicity groups. For each racial/ethnic group, obese men were oldest and non-obese men were the youngest. After age-adjustment, the prevalence of current smoking and cotinine concentration indicative of active smoking, tended to be lowest in the obese men and highest in the non-obese men in each racial/ethnic group; the prevalence of current smoking tended to be highest in NHB men. The prevalence of a lack of physical activity was highest in the obese and lowest in the non-obese categories in each racial/ethnic group, with the exception 
of NHB men. The prevalence of not drinking alcohol was highest in obese men and lowest in non-obese men in each racial/ethnic group; the prevalence of non-drinking was the highest in NHB men in each joint category of overall and central body fatness.

Racial/ethnic differences in the association of percent body fat and waist circumference with sex steroid hormones and metabolic factors

Table 2 presents the association of percent body fat and waist circumference with natural logarithm transformed sex steroid hormones and metabolic factors. Before their simultaneous adjustment, both percent body fat and waist circumference were inversely associated with total testosterone, calculated free testosterone, SHBG, HDL cholesterol, and IGF-1; and positively associated with free estradiol, fasting insulin, total cholesterol, LDL cholesterol, and leptin in each racial/ethnic group. Both percent body fat and waist circumference were positively associated with being above the limit of detection for C-reactive protein in all three racial/ethnic groups.

To determine whether overall body fat or central body fat was more strongly associated with the circulating factors by race/ethnicity, we simultaneously adjusted them for the other. Percent body fat and waist circumference both remained strongly positively associated only with leptin; these associations were similar in all three racial/ethnic groups. Only waist circumference remained clearly inversely associated with total testosterone, SHBG, and HDL cholesterol, and positively associated with free estradiol and fasting insulin in each racial/ethnic group. Only percent body fat remained positively associated with total and free estradiol primarily in NHB men. These associations are summarized in Table 3.

Geometric mean concentrations of sex steroid hormone and metabolic factors by joint categories of overall and central body fatness within racial/ethnic groups are presented in an Online Supplement (Appendices 1 and 2 in Supplementary File).

No significant pattern was observed for total-, freetestosterone, SHBG, C-reactive protein > LOD, total cholesterol, LDL cholesterol, HDL and leptin concentrations. In Appendix 1 mean total and free estradiol concentrations appeared to be highest in the obese category and lowest in the non-obese category among NHW and among NHB men, but total and free estradiol levels were similar in the obese and non-obese categories among MA men (P-interaction = 0.002). In Appendix 2, IGFBP-3 was lowest in the obese and obese by one measure categories than in the non-obese category especially for NHW and MA men (P-interaction = 0.005).

\section{Discussion}

We examined whether the associations of overall and central body fatness with sex steroid hormones and metabolic factors differ by race/ethnicity. In general, waist circumference, a measure of visceral adiposity, appeared to be more consistently associated with these circulating factors than percent body fat in each racial/ethnic group when we simultaneously adjusted for percent body fat and waist circumference to determine their independent associations. We did identify a few exceptions, including a positive association between percent body fat, but not waist circumference, and free estradiol in NHB men only. Although there were no strong associations, the significance of this work was the opportunity to investigate and identify some signicant interactions between race/ethnicity and body fatness and their associations with hormones and metabolic factors.

Racial/ethnic differences in the association between body fatness and circulating hormones and metabolic factors have been previously investigated by using a single body fatness measure (BMI, percent body fat, or waist circumference) (22-26). However, we chose to use percent body fat in this analysis because the correlation between BMI and the amount of body fat differs by race/ethnicity (11).

Our findings are consistent with a previous study conducted by Kupelian et al. showing an inverse association between waist circumference and total and calculated free testosterone and SHBG among NHW, NHB and Hispanic men in a population-based epidemiologic survey (27). Two small studies focused only on SHBG levels, and found an inverse association with waist-to-hip ratio among racial and ethnic groups $(28,29)$. We and other colleagues have previously reported racial/ethnic differences in total testosterone, total estradiol and SHBG levels $(10,30)$, and in a subsequent study we found independent associations between sex steroid hormones and percent body fat ( 9 , 31). Due to a paucity of studies investigating the role of joint categories of overall and central body fatness on sex steroid hormones by race and ethnicity, we cannot make direct comparisons of our findings with other studies.

Our findings investigating the interplay between waist circumference, percent body fat, and metabolic factors are also consistent with previous studies (27, 32-37). Most of these previous studies were conducted using BMI with similar findings among different racial and ethnic groups (33, $34,38-43)$. We found higher insulin concentrations in men who were obese, and lowest in non-obese, among NHWs and MAs, but unexpectedly insulin concentrations did not differ across body fatness categories in NHBs.

Why the association of obesity with some sex steroid 
Table 1. Age-Adjusted Characteristics of 1,243 Men by Joint Categories of Overall and Central Body Fatness, NHANES III (Phase I), 1988 - $1991^{\text {a,b }}$

\begin{tabular}{|c|c|c|c|c|c|c|c|c|c|}
\hline \multirow[t]{3}{*}{ Variables } & \multirow{2}{*}{\multicolumn{3}{|c|}{$\begin{array}{c}\text { Obese by Both Measures } \\
\operatorname{HPBF}(\geq 25 \%) \text { and } \mathrm{HWC}(\geq 102 \mathrm{~cm})\end{array}$}} & \multicolumn{3}{|c|}{ Obese by One Measure Only } & \multirow{2}{*}{\multicolumn{3}{|c|}{$\begin{array}{c}\text { Non-Obese by Both Measures } \\
\operatorname{NPBF}(<25 \%) \text { and } \operatorname{NWC}(<102 \mathrm{~cm})\end{array}$}} \\
\hline & & & & \multirow{2}{*}{$\begin{array}{c}\mathrm{HPBF}(\geq 25 \%) \text { and } \mathrm{NWC}(<102 \mathrm{~cm}) \\
\text { NHW }\end{array}$} & \multirow{2}{*}{$\begin{array}{l}\mathrm{OR} \\
\mathrm{NHB}\end{array}$} & \multirow{2}{*}{$\begin{array}{c}\operatorname{NPBF}(<25 \%) \text { and } \mathrm{HWC}(\geq 102 \mathrm{~cm}) \\
\text { MA }\end{array}$} & & & \\
\hline & NHW & NHB & МА & & & & NHW & NHB & МА \\
\hline No. participants & 174 & 61 & 83 & 167 & 102 & 142 & 262 & 148 & 104 \\
\hline Age, $y$ & $50.1(1.7)$ & $42.1(2.4)$ & $43.6(2.0)$ & $43.4(1.4)$ & $41.8(1.7)$ & $34.9(0.8)$ & $38.3(0.9)$ & $37.6(1.6)$ & $33.3(1.4)$ \\
\hline BMI, $\mathrm{kg} / \mathrm{m}^{2}$ & $32.5(0.6)$ & $35.1(1.0)$ & $32.0(0.5)$ & $26.3(0.1)$ & $26.4(0.4)$ & $26.0(0.2)$ & $23.4(0.2)$ & $23.1(0.2)$ & $23.5(0.5)$ \\
\hline Percent body fat, \% & $30.8(0.3)$ & $32.6(0.7)$ & $31.8(0.6)$ & $27.3(0.3)$ & $28.7(0.5)$ & $28.6(0.2)$ & $20.4(0.2)$ & $20.7(0.4)$ & $21.4(0.4)$ \\
\hline Waist, $\mathrm{cm}$ & $112.2(1.2)$ & $113.9(1.7)$ & $109.0(1.3)$ & $95.7(0.4)$ & $92.0(0.9)$ & $92.5(0.5)$ & $86.7(0.4)$ & $82.1(0.6)$ & $85.6(1.1)$ \\
\hline Weight, lbs & $228.3(5.2)$ & $244.6(7.1)$ & $205.4(3.4)$ & $181.7(1.3)$ & $179.2(3.3)$ & $161.3(2.2)$ & $160.6(1.4)$ & $157.0(1.7)$ & $150.6(3.5)$ \\
\hline Height, in & $70.3(0.3)$ & $70.0(0.2)$ & $67.3(0.4)$ & $69.7(0.2)$ & $69.1(0.3)$ & $66.1(0.3)$ & $69.5(0.2)$ & $69.2(0.3)$ & $67.3(0.4)$ \\
\hline \multicolumn{10}{|l|}{ Cigarette smoking status } \\
\hline Never & 29.6 & 43.5 & 36.8 & 33.6 & 41.8 & 46.2 & 35.8 & 32.6 & 45.5 \\
\hline Former & 41.7 & 22.5 & 40.7 & 35.3 & 26.3 & 28.2 & 30.1 & 18.9 & 17.8 \\
\hline Current & 28.7 & 34.0 & 22.5 & 31.1 & 31.9 & 25.6 & 34.1 & 48.5 & 36.7 \\
\hline \multicolumn{10}{|l|}{$\begin{array}{l}\text { Serum cotinine level (tobacco } \\
\text { smoke exposure), ng/mL }\end{array}$} \\
\hline$<0.35$ (none) & 32.7 & 24.4 & 50.9 & 34.5 & 29.6 & 57.5 & 36.7 & 24.0 & 43.6 \\
\hline $0.35-9.99$ (passive) & 31.5 & 35.7 & 26.1 & 24.0 & 28.6 & 20.6 & 24.3 & 26.4 & 18.8 \\
\hline$\geq 10$ (active) & 35.8 & 39.9 & 23.0 & 41.5 & 41.8 & 21.9 & 39.0 & 49.6 & 37.6 \\
\hline \multicolumn{10}{|c|}{$\begin{array}{l}\text { Moderate and vigorous physical } \\
\text { activity, times/w }\end{array}$} \\
\hline 0 & 11.2 & 8.6 & 29.2 & 7.0 & 4.9 & 25.8 & 4.5 & 9.5 & 17.3 \\
\hline $1-2$ & 35.3 & 30.2 & 36.6 & 25.6 & 24.8 & 34.6 & 23.9 & 20.7 & 32.8 \\
\hline $3-7$ & 25.8 & 25.5 & 19.6 & 29.5 & 39.1 & 18.5 & 25.7 & 20.6 & 21.7 \\
\hline$>7$ & 27.7 & 35.7 & 14.6 & 37.9 & 31.2 & 21.1 & 45.9 & 49.2 & 28.2 \\
\hline \multicolumn{10}{|l|}{$\begin{array}{l}\text { Alcohol consumption, } \\
\text { drinks/month }\end{array}$} \\
\hline 0 & 36.7 & 45.7 & 37.3 & 29.1 & 42.3 & 32.2 & 26.9 & 33.0 & 21.2 \\
\hline $1-30$ & 46.2 & 39.3 & 53.4 & 51.5 & 46.8 & 48.6 & 55.8 & 47.4 & 60.4 \\
\hline$>30$ & 17.1 & 15.0 & 9.3 & 19.4 & 10.9 & 19.2 & 17.3 & 19.6 & 18.4 \\
\hline
\end{tabular}

Abbreviations: $\mathrm{HPBF}$, high percent body fat; $\mathrm{HWC}$, high waist circumference; $\mathrm{NPBF}$, normal percent body fat; $\mathrm{NWC}$, normal waist circumference.

${ }^{a}$ Adjusted for age in years (continuous).

$\mathrm{b}$ Values are expressed as No. (\%) or \%.

hormones and metabolic factors differed by race/ethnicity even after taking into account residual differences in the amount of overall and central obesity is unclear. One possibility is that despite similar BMI, percent body fat, waist circumference, racial/ethnic differences in visceral and subcutaneous adipose tissue may exist (44). Indeed, a large prospective study showed differences between white and black men in visceral and subcutaneous adipose tissue as measured by computed tomography after adjusting with percent body fat, BMI, waist circumference, or WHR (45). These findings have important implications because visceral adipose tissue is reported to be more metabolically active than other adipose tissue sites (46) and possibly contribute to other metabolic abnormalities associated with weight gain $(6,47,48)$.

Our study has a number of strengths. NHANES III is a cross-sectional study representative of the civilian noninstitutionalized US population, which aids in the generalizability of these results. Despites these strengths, the current study has some possible limitations. First, we relied on a single time point measurement of sex steroid hormones and metabolic factors. In addition, measurement of testosterone was obtained with electrochemiluminescence immunoassays not HPLC tandem mass spectrophotometry. Second, the cross-sectional study design doesn't allow us to infer temporality. Third, while we adjusted for factors for which the prevalence differs by race/ethnicity and that are correlates of obesity, such as physical activity and smoking status, residual confounding may have influenced the observed associations. Fourth, measurements of percent body fat and waist circumference are surrogate markers and may not fully capture the total amount of body fat or the location of excess body fat. Fifth, in NHANES III, the percent body fat equation has not been validated in MA men; we used the equation for NHW men. Finally, we cannot rule out that these findings may be due to change, however, adjustment for multiple comparisons was not conducted due to the exploratory nature of this study. 
Table 2. Association of Overall and Central Body Fatness with Circulating Sex Steroid Hormones and Metabolic Factors by Race/Ethnicity, NHANES III (Phase I), 1988 - 1991

\begin{tabular}{|c|c|c|c|c|c|c|c|c|}
\hline \multirow{3}{*}{ Natural Logarithm Transformed Concentration } & \multicolumn{4}{|c|}{ Overall Body Fatness (\% Body Fat) } & \multicolumn{4}{|c|}{ Central Body Fatness (WC) } \\
\hline & \multicolumn{2}{|c|}{ Model 1 $^{\mathrm{a}}$} & \multicolumn{2}{|c|}{ Model $2^{b}$ for WC } & \multicolumn{2}{|c|}{ Model 1} & \multicolumn{2}{|c|}{ Model 2 for PBF } \\
\hline & $\beta$ & PValue & $\beta$ & PValue & $\beta$ & PValue & $\beta$ & PValue \\
\hline \multicolumn{9}{|c|}{ Sex-Steroid Hormones } \\
\hline \multicolumn{9}{|l|}{ Testosterone, ng/mL } \\
\hline NHW & -0.017 & $<0.0001$ & -0.0020 & 0.49 & -0.010 & $<0.0001$ & -0.0090 & $<0.0001$ \\
\hline NHB & -0.017 & $<0.0001$ & -0.0033 & 0.33 & -0.010 & $<0.0001$ & -0.0093 & $<0.0001$ \\
\hline MA & -0.016 & $<0.0001$ & -0.0020 & 0.47 & -0.010 & $<0.0001$ & -0.0089 & $<0.0001$ \\
\hline P-interaction & \multicolumn{2}{|c|}{0.20} & \multicolumn{2}{|c|}{0.06} & \multicolumn{2}{|c|}{0.11} & \multicolumn{2}{|c|}{0.10} \\
\hline \multicolumn{9}{|l|}{ Free Testosterone, ng/mL } \\
\hline NHW & -0.006 & 0.03 & 0.0002 & 0.94 & -0.003 & 0.001 & -0.0034 & 0.009 \\
\hline NHB & -0.005 & 0.09 & 0.0001 & 0.99 & -0.003 & 0.004 & -0.0034 & 0.008 \\
\hline MA & -0.004 & 0.19 & 0.0016 & 0.62 & -0.003 & 0.008 & -0.0029 & 0.03 \\
\hline P-interaction & \multicolumn{2}{|c|}{0.17} & \multicolumn{2}{|c|}{0.14} & \multicolumn{2}{|c|}{0.36} & \multicolumn{2}{|c|}{0.37} \\
\hline \multicolumn{9}{|l|}{ Estradiol, pg/mL } \\
\hline NHW & 0.003 & 0.06 & 0.0031 & 0.24 & 0.001 & 0.17 & -0.0001 & 0.93 \\
\hline NHB & 0.007 & .0007 & 0.0075 & 0.02 & 0.002 & 0.003 & 0.0012 & 0.29 \\
\hline MA & 0.001 & 0.68 & 0.0009 & 0.75 & 0.001 & 0.59 & -0.0007 & 0.56 \\
\hline P-interaction & \multicolumn{2}{|c|}{0.047} & \multicolumn{2}{|c|}{0.04} & \multicolumn{2}{|c|}{0.34} & \multicolumn{2}{|c|}{0.34} \\
\hline \multicolumn{9}{|l|}{ Free Estradiol, pg/mL } \\
\hline NHW & 0.011 & $<0.0001$ & 0.0043 & 0.14 & 0.005 & $<0.0001$ & 0.0037 & 0.009 \\
\hline NHB & 0.016 & $<0.0001$ & 0.0099 & 0.005 & 0.007 & $<0.0001$ & 0.0053 & 0.0004 \\
\hline MA & 0.009 & 0.0009 & 0.0030 & 0.33 & 0.005 & $<0.0001$ & 0.0033 & 0.03 \\
\hline P-interaction & \multicolumn{2}{|c|}{0.18} & & & & & & \\
\hline SHBG, nmol/L & & & & & & & & \\
\hline NHW & -0.024 & $<0.0001$ & -0.0056 & 0.19 & -0.013 & $<0.0001$ & -0.0107 & $<0.0001$ \\
\hline NHB & -0.023 & $<0.0001$ & -0.0065 & 0.11 & -0.013 & $<0.0001$ & -0.0110 & $<0.0001$ \\
\hline MA & -0.024 & $<0.0001$ & -0.0079 & 0.05 & -0.013 & $<0.0001$ & -0.0114 & $<0.0001$ \\
\hline P-interaction & & & & & & & & \\
\hline & & Metabolic & tors & & & & & \\
\hline Fasting insulin, $\mu \mathbf{U} / \mathbf{m L}$ & & & & & & & & \\
\hline NHW & 0.0447 & $<0.0001$ & 0.0075 & 0.06 & 0.0239 & $<0.0001$ & 0.0215 & $<0.0001$ \\
\hline NHB & 0.0408 & $<0.0001$ & 0.0080 & 0.04 & 0.0242 & $<0.0001$ & 0.0216 & $<0.0001$ \\
\hline MA & 0.0404 & $<0.0001$ & 0.0077 & 0.05 & 0.0241 & $<0.0001$ & 0.0215 & $<0.0001$ \\
\hline P-interaction & & & & & & & & \\
\hline C-reactive protein ${ }^{c}$ & & & & & & & & \\
\hline NHW & 0.0141 & 0.0005 & 0.0083 & 0.09 & 0.0060 & 0.0007 & 0.0032 & 0.08 \\
\hline NHB & 0.0177 & 0.0001 & 0.0126 & 0.02 & 0.0075 & 0.0002 & 0.0044 & 0.02 \\
\hline MA & 0.0143 & 0.0003 & 0.0092 & 0.04 & 0.0064 & 0.0008 & 0.0034 & 0.10 \\
\hline P-interaction & & & & & & & & \\
\hline
\end{tabular}


Lopez DS et al.

Table 2 (Continue). Association of Overall and Central Body Fatness with Circulating Sex Steroid Hormones and Metabolic Factors by Race/Ethnicity, NHANES III (Phase I), 1988 - 1991

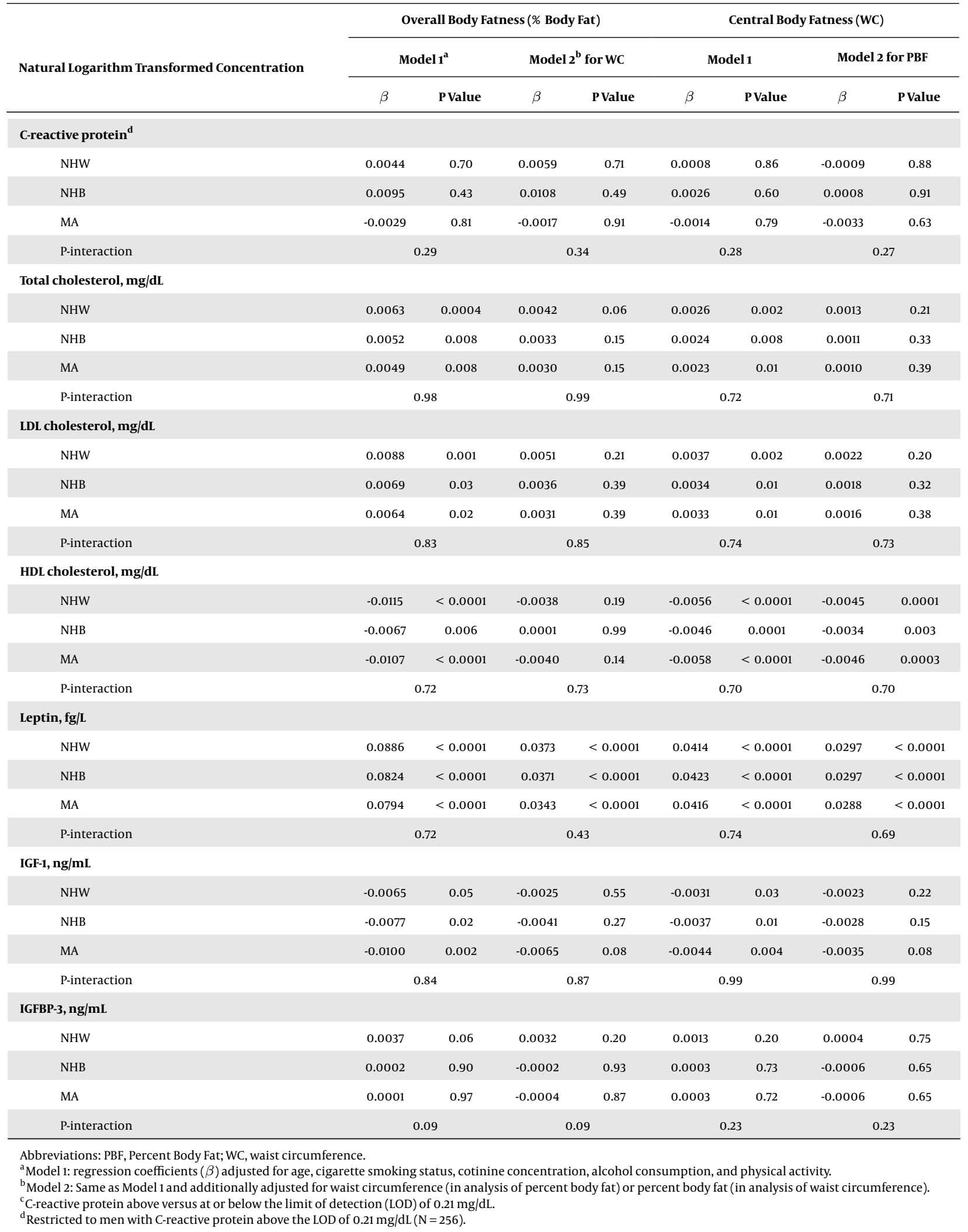


Table 3. Summary of Mutually-Adjusted Associations of Overall and Central Body Fatness with Circulating Concentrations of Sex Steroid Hormones and Metabolic Factors by Race/Ethnicity, Men NHANES III (Phase I), $1988-1991^{\mathrm{a}}$

\begin{tabular}{|c|c|c|c|c|c|c|}
\hline \multirow[t]{2}{*}{ Variables } & \multicolumn{2}{|c|}{ NHW } & \multicolumn{2}{|c|}{ NHB } & \multicolumn{2}{|c|}{ MA } \\
\hline & Percent Body Fat & $\begin{array}{c}\text { Waist } \\
\text { Circumference }\end{array}$ & Percent Body Fat & $\begin{array}{c}\text { Waist } \\
\text { Circumference }\end{array}$ & Percent Body Fat & $\begin{array}{c}\text { Waist } \\
\text { Circumference }\end{array}$ \\
\hline \multicolumn{7}{|l|}{$\begin{array}{l}\text { Sex-steroid } \\
\text { hormones }\end{array}$} \\
\hline $\begin{array}{l}\text { Total } \\
\text { testosterone }\end{array}$ & - & $\downarrow^{\mathrm{b}}$ & - & $\downarrow$ & - & $\downarrow$ \\
\hline $\begin{array}{l}\text { Free } \\
\text { testosterone }\end{array}$ & - & $\downarrow$ & - & $\downarrow$ & - & $\downarrow$ \\
\hline Total estradiol & - & - & $\uparrow^{c}$ & - & - & - \\
\hline Free estradiol & - & $\uparrow$ & $\uparrow$ & $\uparrow$ & - & $\uparrow$ \\
\hline SHBG & - & $\downarrow$ & - & $\downarrow$ & $\downarrow$ & $\downarrow$ \\
\hline \multicolumn{7}{|l|}{ Metabolic factors } \\
\hline $\begin{array}{l}\text { Fasting } \\
\text { insulin }\end{array}$ & $\uparrow$ & $\uparrow$ & $\uparrow$ & $\uparrow$ & $\uparrow$ & $\uparrow$ \\
\hline $\begin{array}{l}\text { C-reactive } \\
\text { protein (> } \\
\text { limit of } \\
\text { detection of } \\
0.21 \mathrm{mg} / \mathrm{dL})\end{array}$ & $\uparrow$ & $\uparrow$ & $\uparrow$ & $\uparrow$ & $\uparrow$ & $\uparrow$ \\
\hline $\begin{array}{l}\text { Total } \\
\text { cholesterol }\end{array}$ & $\uparrow$ & - & - & - & - & - \\
\hline $\begin{array}{l}\text { LDL } \\
\text { cholesterol }\end{array}$ & - & - & - & - & - & - \\
\hline $\begin{array}{l}\text { HDL } \\
\text { cholesterol }\end{array}$ & - & $\downarrow$ & - & $\downarrow$ & - & $\downarrow$ \\
\hline Leptin & $\uparrow$ & $\uparrow$ & $\uparrow$ & $\uparrow$ & $\uparrow$ & $\uparrow$ \\
\hline IGF-1 & - & - & - & - & $\uparrow$ & $\uparrow$ \\
\hline IGFBP-3 & - & - & - & - & - & - \\
\hline
\end{tabular}

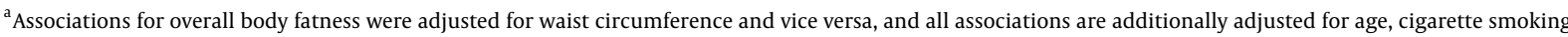
status, cotinine level, alcohol consumption, and physical activity.

${ }^{\mathrm{b}}$ Denotes a statistically significant inverse association. Arrow without an asterisk denotes a possible association $(0.05 \leq \mathrm{P} \leq 0.10)$.

${ }^{\mathrm{c}}$ Denotes a statistically significant positive association.

In conclusion, we found that the patterns of association of overall and central body fatness with circulating hormones and metabolic factors were similar by race/ethnicity in men, with a few notable exceptions that are important, but cannot be further teased out in this study including because adipose tissue compartment (i.e., visceral and subcutaneous adipose tissue) were not measured. These findings highlight the importance of the analysis of body fatness and risk of cancer and other conditions by race/ethnicity.

\section{Supplementary Material}

Supplementary material(s) is available here.

\section{Acknowledgments}

This is the 25th study from the Hormone Demonstration Program funded by the Maryland Cigarette Restitution Fund at Johns Hopkins (Nelson). The work was also supported by NCI P30 CA006973 (Nelson). Dr. Lopez was supported by a National Research Service Award T32 CA009314 (Platz) from the National Cancer Institute. The content of this work is solely the responsibility of the authors and does not necessarily represent the official views of the Maryland Department of Health and Mental Hygiene or the National Institutes of Health.

\section{Footnotes}

Financial Disclosure: None.

Conflict of Interest: None. 


\section{References}

1. Flegal KM, Carroll MD, Kit BK, Ogden CL. Prevalence of obesity and trends in the distribution of body mass index among US adults, 19992010. JAMA. 2012;307(5):491-7. doi: 10.1001/jama.2012.39. [PubMed: 22253363].

2. Flegal KM, Carroll MD, Ogden CL, Curtin LR. Prevalence and trends in obesity among US adults, 1999-2008. JAMA. 2010;303(3):235-41. doi: 10.1001/jama.2009.2014. [PubMed: 20071471].

3. Calle EE, Kaaks R. Overweight, obesity and cancer: epidemiological evidence and proposed mechanisms. Nat Rev Cancer. 2004;4(8):579-91. doi: 10.1038/nrc1408. [PubMed:15286738].

4. Siegel R, Naishadham D, Jemal A. Cancer statistics for Hispanics/Latinos, 2012. CA Cancer J Clin. 2012;62(5):283-98. doi: 10.3322/caac.21153. [PubMed: 22987332].

5. Mozaffarian D, Benjamin EJ, Go AS, Arnett DK, Blaha MJ, Cushman M, et al. Heart disease and stroke statistics-2015 update: a report from the American Heart Association. Circulation. 2015;131(4):e29-322. doi: 10.1161/CIR.0000000000000152. [PubMed: 25520374].

6. Berg AH, Scherer PE. Adipose tissue, inflammation, and cardiovascular disease. Circ Res. 2005;96(9):939-49. doi: 10.1161/01.RES.0000163635.62927.34. [PubMed: 15890981].

7. Derby CA, Zilber S, Brambilla D, Morales KH, McKinlay JB. Body mass index, waist circumference and waist to hip ratio and change in sex steroid hormones: the Massachusetts Male Ageing Study. Clin Endocrinol (Oxf). 2006;65(1):125-31. doi: 10.1111/j.1365-2265.2006.02560.x. [PubMed: 16817831].

8. Gallagher EJ, LeRoith D. Insulin, insulin resistance, obesity, and cancer. Curr Diab Rep. 2010;10(2):93-100. doi: 10.1007/s11892-010-0101-y. [PubMed: 20425567].

9. Rohrmann S, Shiels MS, Lopez DS, Rifai N, Nelson WG, Kanarek N, et al. Body fatness and sex steroid hormone concentrations in US men: results from NHANES III. Cancer Causes Control. 2011;22(8):1141-51. doi: 10.1007/s10552-011-9790-z. [PubMed: 21678033].

10. Rohrmann S, Nelson WG, Rifai N, Brown TR, Dobs A, Kanarek N, et al. Serum estrogen, but not testosterone, levels differ between black and white men in a nationally representative sample of Americans. J Clin Endocrinol Metab. 2007;92(7):2519-25. doi: 10.1210/jc.2007-0028. [PubMed: 17456570].

11. Flegal KM, Shepherd JA, Looker AC, Graubard BI, Borrud LG, Ogden $\mathrm{CL}$, et al. Comparisons of percentage body fat, body mass index, waist circumference, and waist-stature ratio in adults. Am J Clin Nutr. 2009;89(2):500-8. doi: 10.3945/ajcn.2008.26847. [PubMed: 19116329].

12. American Cancer Society . Cancer Facts \& Figures for Hispanics/Latinos 2012-2014. Atlanta: American Cancer Society; 2012.

13. National Center for Health Statistics . Plan and operation of the third national health and nutrition examination survey, 1988-94. series 1 : Programs and collection procedures. Vital health stat; 1994.

14. Chumlea WC, Guo SS, Kuczmarski RJ, Flegal KM, Johnson CL, Heymsfield SB, et al. Body composition estimates from NHANES III bioelectrical impedance data. Int J Obes Relat Metab Disord. 2002;26(12):1596609. doi: 10.1038/sj.ijo.0802167. [PubMed: 12461676].

15. Vermeulen A, Verdonck L, Kaufman JM. A critical evaluation of simple methods for the estimation of free testosterone in serum. J Clin Endocrinol Metab. 1999;84(10):3666-72. doi: 10.1210/jcem.84.10.6079. [PubMed: 10523012].

16. Rinaldi S, Geay A, Dechaud H, Biessy C, Zeleniuch-Jacquotte A, Akhmedkhanov A, et al. Validity of free testosterone and free estradiol determinations in serum samples from postmenopausal women by theoretical calculations. Cancer Epidemiol Biomarkers Prev. 2002;11(10 Pt 1):1065-71. [PubMed: 12376508 ].

17. Ma Z, Gingerich RL, Santiago JV, Klein S, Smith CH, Landt M. Radioimmunoassay of leptin in human plasma. Clin Chem. 1996;42(6 Pt1):9426. [PubMed: 8665687].

18. Berrigan D, Potischman N, Dodd KW, Nicar M, McQuillan G, Lavigne JA, et al. Serum levels of insulin-like growth factor-I and insulin- like growth factor-I binding protein-3: quality control for studies of stored serum. Cancer Epidemiol Biomarkers Prev. 2007;16(5):1017-22. doi:10.1158/1055-9965.EPI-07-0044. [PubMed:17507631]

19. Shah BV, Barnwell G, Bieler GS. In: Research Triangle Park. Shah BV Barnwell G, Bieler GS, editors. Research Triangle Institute; 1997. SUDAAN user's manual, release 8.0.

20. Deurenberg P, Andreoli A, Borg P, Kukkonen-Harjula K, de Lorenzo A, van Marken Lichtenbelt WD, et al. The validity of predicted body fat percentage from body mass index and from impedance in samples of five European populations. Eur J Clin Nutr. 2001;55(11):973-9. doi: 10.1038/sj.ejcn.1601254. [PubMed: 11641746].

21. Ford ES, Giles WH, Dietz WH. Prevalence of the metabolic syndrome among US adults: findings from the third National Health and Nutrition Examination Survey. JAMA. 2002;287(3):356-9. [PubMed: 11790215].

22. Vermeulen A, Goemaere S, Kaufman JM. Testosterone, body composition and aging. J Endocrinol Invest. 1999;22(5 Suppl):110-6. [PubMed: 10442580]

23. Field AE, Colditz GA, Willett WC, Longcope C, McKinlay JB. The relation of smoking, age, relative weight, and dietary intake to serum adrenal steroids, sex hormones, and sex hormone-binding globulin in middle-aged men. J Clin Endocrinol Metab. 1994;79(5):1310-6. doi 10.1210/jcem.79.5.7962322. [PubMed: 7962322].

24. Gapstur SM, Gann PH, Kopp P, Colangelo L, Longcope C, Liu K. Serum androgen concentrations in young men: a longitudinal analysis of associations with age, obesity, and race. The CARDIA male hormone study. Cancer Epidemiol Biomarkers Prev. 2002;11(10 Pt 1):1041-7. [PubMed: 12376505].

25. Svartberg J, Midtby M, Bonaa KH, Sundsfjord J, Joakimsen RM Jorde R. The associations of age, lifestyle factors and chronic disease with testosterone in men: the Tromso Study. Eur J Endocrinol. 2003;149(2):145-52. [PubMed: 12887292].

26. Travison TG, Araujo AB, Kupelian V, O'Donnell AB, McKinlay JB. The relative contributions of aging, health, and lifestyle factors to serum testosterone decline in men. J Clin Endocrinol Metab. 2007;92(2):54955. doi: 10.1210/jc.2006-1859. [PubMed:17148559].

27. Kupelian V, Hayes FJ, Link CL, Rosen R, McKinlay JB. Inverse association of testosterone and the metabolic syndrome in men is consistent across race and ethnic groups. J Clin Endocrinol Metab. 2008;93(9):3403-10. doi:10.1210/jc.2008-0054. [PubMed: 18559915].

28. Winters SJ, Brufsky A, Weissfeld J, Trump DL, Dyky MA, Hadeed V. Testosterone, sex hormone-binding globulin, and body composition in young adult African American and Caucasian men. Metabolism. 2001;50(10):1242-7. doi:10.1053/meta.2001.26714. [PubMed: 11586501].

29. Heald AH, Anderson SG, Ivison F, Riste L, Laing I, Cruickshank JK, et al. Low sex hormone binding globulin is a potential marker for the metabolic syndrome in different ethnic groups. Exp Clin Endocrinol Diabetes. 2005;113(9):522-8. doi: 10.1055/s-2005-865807. [PubMed: 16235154].

30. Lopez DS, Peskoe SB, Joshu CE, Dobs A, Feinleib M, Kanarek N, et al. Racial/ethnic differences in serum sex steroid hormone concentrations in US adolescent males. Cancer Causes Control. 2013;24(4):817-26. doi: 10.1007/s10552-013-0154-8. [PubMed: 23354421].

31. Trabert B, Graubard BI, Nyante SJ, Rifai N, Bradwin G, Platz EA, et al Relationship of sex steroid hormones with body size and with body composition measured by dual-energy X-ray absorptiometry in US men. Cancer Causes Control. 2012;23(12):1881-91. doi: 10.1007/s10552012-0024-9. [PubMed: 23053790].

32. Sun Q, van Dam RM, Spiegelman D, Heymsfield SB, Willett WC, Hu FB. Comparison of dual-energy x-ray absorptiometric and anthropometric measures of adiposity in relation to adiposity-related biologic factors. Am J Epidemiol. 2010;172(12):1442-54. doi: 10.1093/aje/kwq306. [PubMed: 20952596].

33. McAdams MA, Van Dam RM, Hu FB. Comparison of self-reported and measured BMI as correlates of disease markers in US adults. Obesity 
(Silver Spring). 2007;15(1):188-96. doi: 10.1038/oby.2007.504. [PubMed: 17228047].

34. Wee CC, Mukamal KJ, Huang A, Davis RB, McCarthy EP, Mittleman MA. Obesity and C-reactive protein levels among white, black, and hispanic US adults. Obesity (Silver Spring). 2008;16(4):875-80. doi: 10.1038/oby.2008.7. [PubMed: 18379563].

35. Vickers MH, Ikenasio BA, Breier BH. IGF-I treatment reduces hyperphagia, obesity, and hypertension in metabolic disorders induced by fetal programming. Endocrinology. 2001;142(9):3964-73. doi: 10.1210/endo.142.9.8390. [PubMed: 11517175].

36. Bann D, Holly JM, Lashen H, Hardy R, Adams J, Kuh D, et al. Changes in insulin-like growth factor-I and -II associated with fat but not lean mass in early old age. Obesity (Silver Spring). 2015;23(3):692-8. doi: 10.1002/oby.21002. [PubMed: 25645314].

37. Savastano S, Angrisani L, Di Somma C, Rota F, Savanelli MC, Cascella $\mathrm{T}$, et al. Relationship between growth hormone/insulin-like growth factor-1 axis integrity and voluntary weight loss after gastric banding surgery for severe obesity. Obes Surg. 2010;20(2):211-20. doi: 10.1007/s11695-009-9926-3. [PubMed: 19636643].

38. Carnethon MR, Palaniappan LP, Burchfiel CM, Brancati FL, Fortmann SP. Serum insulin, obesity, and the incidence of type 2 diabetes in black and white adults: the atherosclerosis risk in communities study: 1987-1998. Diabetes Care. 2002;25(8):1358-64. [PubMed: 12145235].

39. Palaniappan LP, Carnethon MR, Fortmann SP. Heterogeneity in the relationship between ethnicity, BMI, and fasting insulin. Diabetes Care 2002;25(8):1351-7. [PubMed: 12145234].

40. Colangelo LA, Chiu B, Kopp P, Liu K, Gapstur SM. Serum IGF-I and C-reactive protein in healthy black and white young men: the CARDIA male hormone study. Growth Horm IGF Res. 2009;19(5):420-5. doi: 10.1016/j.ghir.2008.12.002. [PubMed: 19138871].
41. Despres JP, Couillard C, Gagnon J, Bergeron J, Leon AS, Rao DC, et al. Race, visceral adipose tissue, plasma lipids, and lipoprotein lipase activity in men and women: the Health, Risk Factors, Exercise Training, and Genetics (HERITAGE) family study. Arterioscler Thromb Vasc Biol. 2000;20(8):1932-8. [PubMed: 10938014].

42. Norman JE, Bild D, Lewis CE, Liu K, West DS, Cardia Study . The impact of weight change on cardiovascular disease risk factors in young black and white adults: the CARDIA study. Int J Obes Relat Metab Disord. 2003;27(3):369-76. doi: 10.1038/sj.ijo.0802243. [PubMed: 12629565].

43. Henderson KD, Goran MI, Kolonel LN, Henderson BE, Le Marchand L. Ethnic disparity in the relationship between obesity and plasma insulin-like growth factors: the multiethnic cohort. Cancer Epidemiol Biomarkers Prev. 2006;15(11):2298-302. doi: 10.1158/1055-9965.EPI-060344. [PubMed: 17119061].

44. Carroll JF, Chiapa AL, Rodriquez M, Phelps DR, Cardarelli KM, Vishwanatha JK, et al. Visceral fat, waist circumference, and BMI: impact of race/ethnicity. Obesity (Silver Spring). 2008;16(3):600-7. doi: 10.1038/oby.2007.92. [PubMed: 18239557].

45. Hill JO, Sidney S, Lewis CE, Tolan K, Scherzinger AL, Stamm ER. Racial differences in amounts of visceral adipose tissue in young adults: the CARDIA (Coronary Artery Risk Development in Young Adults) study. Am J Clin Nutr. 1999;69(3):381-7. [PubMed: 10075320].

46. Jensen MD. Adipose tissue and fatty acid metabolism in humans. $J R$ Soc Med. 2002;95 Suppl 42:3-7. [PubMed: 12216324].

47. Ross R, Fortier L, Hudson R. Separate associations between visceral and subcutaneous adipose tissue distribution, insulin and glucose levels in obese women. Diabetes Care. 1996;19(12):1404-11. [PubMed: 8941472].

48. Bonora E. Relationship between regional fat distribution and insulin resistance. Int J Obes Relat Metab Disord. 2000;24 Suppl 2:S32-5. [PubMed: 10997605]. 